\title{
PESQUISA EM EDUCAÇÃO AMBIENTAL E QUESTÕES EPISTEMOLÓGICAS: A NECESSIDADE DA CONTINUIDADE DO DEBATE
}

Rosa Maria Feiteiro Cavalari ${ }^{1}$

Eunice Schilling Trein ${ }^{2}$

\section{Resumo}

Neste artigo expomos as discussões ocorridas no âmbito do Grupo de Discussão de Pesquisa (GDP) Pesquisa em EA e Questões Epistemológicas, durante o VIII Encontro de Pesquisa em Educação Ambiental (VIII EPEA), realizado no Rio de Janeiro (RJ), no período de 19 a 22 de julho de 2015, que teve como tema A Avaliação da Década da Educação para o Desenvolvimento Sustentável e Perspectivas futuras. Para tanto, além de retomarmos algumas questões apresentadas em encontros anteriores, procuramos apresentar uma síntese dos trabalhos inscritos, bem como das temáticas abordadas.

Palavras-chave: Questões Epistemológicas. Pesquisa em Educação Ambiental. Grupo de Discussão de Pesquisa (GDP). Educação Ambiental.

\section{RESEARCH IN ENVIRONMENTAL EDUCATION AND EPISTEMOLOGICAL QUESTIONS: THE NEED FOR CONTINUITY THE DEBATE}

\begin{abstract}
This paper exposed the discussions held within the Research Group Discussion (GDP) Research in the EA and Epistemological Questions, during the VIII Meeting of Research in Environmental Education (VIII EPEA), held in Rio de Janeiro (RJ), from 19 to 22 July 2015, which had the theme The Decade of Education Assessment for Sustainable Development and future Prospects. Therefore, in addition to resume some issues raised in previous meetings, we try to present a summary of the work submitted, as well as the issues addressed.
\end{abstract}

Keywords: Epistemological issues. Research in Environmental Education. Group Discussion Research (GDP). Environmental education.

\section{LA INVESTIGACIÓN EN EDUCACIÓN AMBIENTAL Y CUESTIONES EPISTEMOLÓGICAS: LA NECESIDAD DE CONTINUAR EL DEBATE}

\section{Resumen}

En este artículo, se exponen los debates celebrados en la discusión del Grupo de Discusión de Pesquisas (GDP) Investigación en EA y Cuestiones Epistemológicas, durante el VIII Encuentro de Investigación en Educación Ambiental (EPEA VIII), relizado en Río de Janeiro (RJ), entre el 19 y 22 de julio de 2015, que eligió el tema La Evaluación de la Década de la Educación para el Desarrollo Sostenible y las Perspectivas Futuras. Por lo tanto, además de retomar algunas cuestiones planteadas en reuniones anteriores, tratamos de presentar un resumen de los trabajos presentados, así como los temas abordados.

\footnotetext{
${ }^{1}$ Professora Assistente Doutora, da Universidade Estadual Paulista “Júlio Mesquita Filho" (UNESP) Câmpus de Rio Claro, São Paulo, Brasil, rosamfc@rc.unesp.br

2 Professora Associada I, da Universidade Federal Fluminense (UFF), Rio de Janeiro, Brasil, eunicetrein@ig.com.br
} 
Palabras-clave: Cuestiones epistemológicas. Investigación en Educación Ambiental. Grupo de Discusión de Pesquisa (GDP). Educación ambiental.

\section{Introdução}

O tema central do VIII EPEA - A Avaliação da Década da Educação para o Desenvolvimento Sustentável e Perspectivas Futuras, bem como as conferências e debates ocorridos durante o evento, mais uma vez explicitaram a importância de nos ocuparmos das questões epistemológicas na dimensão já destacada por Floriani (2009), ou seja, que é preciso superar as dificuldades próprias dos diversos campos do conhecimento e buscar aprofundar e desenvolver novas culturas epistemológicas, sem que isto implique em buscar um paradigma hegemônico na EA.

No artigo, resgatamos algumas questões que já foram apresentadas em encontros anteriores e apresentamos o relato dos oito trabalhos inscritos e as temáticas abordadas.

\section{Destaques da temática central do evento}

A temática central do encontro esteve presente em todas as discussões, evidenciando, dentre outras coisas, o que justifica a continuidade do GDP como espaço de sistematização da produção em EA e a necessidade de "superar certa perspectiva linear, descritiva dos objetos, métodos e procedimentos da pesquisa e explicitar sentidos e interesses a ela subjacentes (TREIN, 2012, p.87).

Assim, neste texto retomamos, de maneira breve, algumas questões que nos parecem relevantes e que se evidenciaram nos debates ocorridos no GDP, neste encontro e nos EPEAs anteriores (TREIN; CAVALARI, 2014). Isto se faz necessário quando esmiuçamos, por exemplo, as várias acepções do que se entende por EA crítica, teoria crítica, pensamento crítico, práticas educativas críticas e os contextos em que esses conceitos são mobilizados. Já na conferência de abertura do VIII EPEA, Roberto Leher chamou a atenção para vários aspectos que, hoje, condicionam a EA no Brasil e na América Latina. Muitos deles estão sistematizados em seu texto recente: Apresentação: Educação Ambiental como crítica ao desenvolvimento sustentável: desafios dos movimentos e das lutas sociais (LEHER, 2015).

Uma primeira questão que Leher aborda, e nos parece significativa, refere-se à presença, na educação básica, da perspectiva empresarial do Todos pela Educação. Ao apelar indistintamente a todos os segmentos da sociedade para que se ocupem da educação das gerações futuras, se opera um processo de pasteurização das práticas educativas, com um caráter mais crítico, realizadas pelos educadores nas escolas de todo o país. A presença das empresas nas escolas, buscando estabelecer vínculos entre as atividades produtivas de determinados segmentos da economia e a vida dos alunos, seus familiares e a comunidade onde a escola está inserida, reduz o caráter crítico e emancipatório ao jargão do: estamos todos no mesmo barco e precisamos contribuir para um desenvolvimento sustentável que nos beneficiará a todos e que depende igualmente de todos nós. A garantia de que isso se realize passa por procedimentos ditos objetivos, tais como medidas de desempenho, cumprimento de metas, realização de ações previstas em convênios com empresas; todas essas ações atravessam o currículo escolar e desarticulam o planejamento dos professores. No mesmo sentido, como muito bem sintetiza Freitas (2014):

Este conjunto de dispositivos representa o maior avanço dos reformadores empresariais da educação no cenário educacional brasileiro e, entre outros aspectos, visa abrir o campo educacional para "empresas educacionais confiáveis" do mercado de consultoria, materiais didáticos, avaliação, venda de tecnologia, organização de big data entre outras, que operam na difusão de métodos tecnicistas e introduzem nas redes e escolas processos de gestão verticalizadas, que permitem elevar o grau 
de controle sobre os profissionais da educação, a título de garantir a obtenção de metas e índices nas avaliações externas, definindo os objetivos, a avaliação, a forma e o conteúdo da escola (FREITAS, 2014, p.1092).

Essas interferências externas esvaziam, muitas vezes, as práticas educativas de seu sentido crítico e antissistêmico.

Examinar as questões socioambientais a partir de outro ponto de vista, o dos movimentos sociais que estão em luta em defesa de seus direitos materiais, sociais e culturais, certamente traria, para o âmbito da escola e das pesquisas sobre o que nelas acontece, outros questionamentos, novas abordagens; enfim, exigiria outras perspectivas epistemológicas pois os desafios políticos, os interesses subjacentes às pesquisas, demandariam também novos procedimentos metodológicos.

Uma outra questão, desenvolvida por Leher (2015), diz respeito à contradição inerente ao modo de definirmos desenvolvimento e à garantia da sustentabilidade socioambiental. Segundo o autor, a concepção de desenvolvimento forjada nos anos 1970, no continente americano, está fortemente atrelada à perspectiva da industrialização e à sociedade de consumo. Essa perspectiva delineou o lugar de cada país no capitalismo mundializado, baseado em vantagens comparativas que deram a diretriz a Estados, governos, empresas e à sociedade em geral, sobre a forma de relação metabólica que estabelecemos com a natureza e, em decorrência dessas escolhas, elegemos concepções de educação como mais adequadas a tais finalidades do capitalismo dependente.

Acompanhar esses movimentos dos sujeitos sociais do Estado, dos trabalhadores, dos empresários nas diversas formas de relações que cada classe estabelece com os recursos naturais, formas de apropriação, benefícios e prejuízos são e devem continuar sendo temas de pesquisa. Isso exige métodos de análise, uso de conceitos e categorias, procedimentos metodológicos que são norteados por objetivos que respondem a diferentes visões de mundo e não, como querem nos fazer crer, a uma única definição de desenvolvimento sustentável, de educação, de sociedade.

Nessa perspectiva, apresentada tão brevemente, é que consideramos o GDP de Epistemologia como um espaço importante para aprofundar as questões trazidas pelos participantes e que expressam parte do universo da pesquisa na pós-graduação em EA, seus questionamentos e seus dilemas.

\section{Os trabalhos inscritos no GDP - uma síntese comentada}

O GDP Pesquisa em Educação Ambiental e Questões Epistemológicas teve, inscritos para o VIII EPEA, oito trabalhos. Em relação à quantidade de trabalhos inscritos no GDP, houve uma diminuição em relação ao VII EPEA, realizado em Rio Claro, em 2013, no qual foram inscritos onze trabalhos.

Dos oito trabalhos inscritos, três são trabalhos teóricos, e cinco relatos de pesquisas empíricas.

Nos trabalhos teóricos explicita-se, claramente, a opção pela Educação Ambiental Crítica, sendo que, em um deles, explicita-se que o Materialismo-Histórico é adotado como referencial. Nas pesquisas empíricas, embora não haja explicitação clara, todos os trabalhos podem ser compreendidos como pertencentes a uma vertente crítica da Educação e da Educação Ambiental.

Nas pesquisas empíricas, pode-se observar que a pesquisa documental é o tipo mais adotado. Dos cinco trabalhos, apenas um não se caracteriza como pesquisa documental. $\mathrm{O}$ corpus documental desses trabalhos são os seguintes: Revista Veja, periódicos científicos e teses/dissertações em Educação Ambiental (dois trabalhos). 
Em relação à origem desses trabalhos, há uma predominância das regiões Sul e Sudeste. Com exceção de um trabalho, originário da região Nordeste, os sete trabalhos restantes são dessas duas regiões.

Outro aspecto pode ser apontado, com o intuito de apresentar uma caracterização geral desses trabalhos. Trata-se, referente à autoria, da predominância do gênero feminino entre os autores. Dos oito trabalhos inscritos, seis são realizados por mulheres, sendo que, destes, apenas um tem apenas uma autora.

Apresentamos, a seguir, os oito trabalhos inscritos e descrevemos, brevemente, seu objeto de pesquisa, referencial teórico, objetivos e conclusões.

O primeiro trabalho, de caráter mais teórico, busca estabelecer um diálogo com a obra de dois autores que realizaram um esforço de diálogo com a realidade da sociedade latinoamericana a partir dos interesses, preocupações e lutas sociais das populações mais vulneráveis desde a perspectiva socioambiental.

O trabalho Interculturalidade, exclusão e libertação em Paulo Freire na leitura de Enrique Dussel: aproximações para a pesquisa em educação ambiental crítica, (T 3), de César Augusto Costa (FURG) e Carlos Frederico Loureiro (UFRJ).

De acordo com os autores, pretende-se

[...] a partir da leitura do filósofo argentino Enrique Dussel, refletir alguns aspectos centrais da pedagogia de Paulo Freire e de como ambos contribuem, do ponto de vista epistemológico e político, para aproximações críticas em torno da pesquisa em educação ambiental. Neste sentido, o referido trabalho objetiva compreender a proposta educativa de Paulo Freire à luz da leitura de Enrique Dussel acerca da realidade latino-americana (COSTA; LOUREIRO, 2015, p.1).

Inicialmente, os autores do trabalho analisam a relação intrínseca entre Paulo Freire e Enrique Dussel enquanto críticos radicais do eurocentrismo e que buscam a construção de um genuíno pensamento latino-americano. Posteriormente, os autores se propõem a "[...] refletirem filosoficamente a realidade latino-americana a partir das categorias interculturalidade, exclusão e libertação na compreensão desses autores [...]"'(COSTA; LOUREIRO, 2015, p. 1), entendidas no trabalho como "centrais para se compreender que a educação ambiental (EA) é um ato intencional, praxiológico e, portanto, não é algo espontâneo e sem certo grau de diretividade" (COSTA; LOUREIRO, 2015, p. 7).

Ainda, de acordo com os autores, "para a pesquisa em EA tais categorias contribuem de maneira decisiva apontando que as propostas pluralistas e espontaneístas que estão centradas somente na ação dos indivíduos ferem aquilo que usam como base: a pedagogia libertadora latino-americana" (p. 7).

Ao final, os autores concluem que a

[...] contribuição 'crítico-metodológica' do pensamento de Freire e Dussel para a pesquisa em EA, consiste na crítica à sociedade capitalista ancorada em categorias libertadoras e emancipatórias, acompanhada pelo respeito aos povos originários e tradicionais, sua cultura, seus costumes e modos de produção, firmando o diálogo de saberes que vise o enfrentamento do projeto civilizatório eurocêntrico e possibilite a afirmação de identidades próprias (COSTA; LOUREIRO, 2015, p. 14)

Em um segundo texto, vamos encontrar a preocupação com o discurso empresarial e os vários sentidos que a expressão desenvolvimento sustentável assume nas propagandas veiculadas pela mídia. Para além dos sentidos, a autora busca desvendar, também, as relações de força e de saber que possam existir no objeto de pesquisa.

$\mathrm{O}$ trabalho Reflexões epistemológicas sobre a publicidade sustentável: pesquisa de tese realizada na década da Educação para o Desenvolvimento Sustentável, (T 222) de Dinair Velleda Teixeira, da UFRGS, relata os resultados parciais de uma pesquisa documental realizada no Banco de Dados da Revista Veja. O objetivo da pesquisa é "compreender como 
são construídos e as formas como se movimentam os sentidos de sustentabilidade durante a década" (p.1).

Segundo a autora, por meio da análise dos "[...] anúncios publicitários com foco na sustentabilidade veiculados pela Revista Veja S/A durante a Década da Educação para o Desenvolvimento Sustentável (2005-2014)", (p. 5) o trabalho pretende responder às seguintes questões de pesquisa: "que sentidos de sustentabilidade foram propostos discursivamente pelas organizações através de seus anúncios publicitários; quais estratégias de comunicação foram empregadas nessa construção da Década da Educação para o Desenvolvimento Sustentável (2005-2014) (TEIXEIRA, 2015, p. 5).

Na descrição "do método e técnicas" da pesquisa, a autora informa que na primeira fase realizou-se pesquisa documental em Banco de Dados da Revista Veja S/A, através da abordagem qualitativa e quantitativa na perspectiva dedutiva. A análise foi realizada em 520 edições, referente ao recorte temporal de 2005 a 2014 [...]. Desse material empírico analisado, foram coletados e catalogados somente os anúncios com foco na sustentabilidade. Foi possível apurar que as empresas que mais acionam os sentidos de sustentabilidade em seus anúncios são dos segmentos: bancário (Banco Real), bebida não-alcoólica (Coca-Cola), cosmético (Natura) e mineração (Vale). (TEIXEIRA, 2015, p. 6).

$\mathrm{Na}$ segunda fase, com base na pesquisa exploratória, foram agrupados, em blocos discursivos os anúncios das empresas que mais anunciaram por segmento. Nesse caso, a autora destaca que pode-se

[...] perceber que determinadas marcas nos discursos se apresentavam com mais frequência, se configurando, portanto ideais para agrupá-las: são elas: a) uso explícito do termo sustentabilidade ou desenvolvimento sustentável, b) silenciamento dos termos sustentabilidade e desenvolvimento sustentável, c) uso explícito dos termos transformação ou mudança (TEIXEIRA, 2015, p. 7).

E, finalmente na terceira e última fase da pesquisa, a autora informa que "dada a impossibilidade de análise em profundidade em todos os anúncios, selecionou-se 3 anúncios de cada empresa, para mergulhar nas profundezas desses textos e fazer emergir os sentidos de sustentabilidade ali encobertos" (p.7). Informa, ainda, que "teve-se o cuidado de selecionar anúncios veiculados no início, meio e final da década, para que fosse possível entender os sentidos de sustentabilidade ao longo da década [...]" (TEIXEIRA, 2015, p. 7).

Como lente para olhar o objeto de pesquisa é utilizada a Análise de Discurso francesa Pêcheuxtiana. De acordo com a autora,

[...] esse observatório se constrói em dispositivo para examinar os sentidos de sustentabilidade acionados pelas empresas a partir da materialidade linguística dos anúncios publicitários selecionados, na qual possibilitará olhar não só as relações de sentidos, mas também as relações de força e de saber, que possa existir no objeto (TEIXEIRA, 2015, p. 10).

\section{Como conclusão, a autora afirma que}

[...] Embora a tese não esteja concluída é possível perceber uma mudança na forma dos discursos das organizações ao longo da década, que pode ser entendido como um reflexo dos esforços empreendidos pela UNESCO, com a Década da Educação para o desenvolvimento Sustentável, que se refletiu na forma como a sociedade, na voz de órgãos de preservação do meio ambiente e demais atores sociais estão conduzindo as questões ambientais, com muito mais exigência e atentos aos detalhes (TEIXEIRA, 2015, p. 12).

E explica: 
dos textos aciona sentidos de sustentabilidade com seu dizer, ainda assim, se mantém na FD de Mercado porque a forma-sujeito regula a manutenção dos princípios dessa FD. Assim, a noção de sentido e de sujeito é pensada junta, porque os sentidos são significados a partir do que o sujeito do discurso diz. Portanto, essas noções estão inter-relacionadas e são interdependentes na construção dos sentidos de sustentabilidade posto em movimento nos anúncios (TEIXEIRA, 2015, p. 12).

A autora finaliza o trabalho, afirmando que são "impressões ainda embrionárias, ainda que indiquem alguns movimentos de sentidos" e que "a intenção da pesquisa não é avaliar se as organizações são ou não sustentáveis, mas compreender os sentidos de sustentabilidade acionados por elas, através de como é dito o que elas dizem" (TEIXEIRA, 2015, p. 12).

O terceiro texto investiga, em periódicos nacionais, a presença da obra de Gaston Bachelard e sua contribuição para as bases epistemológicas da EA. As autoras fazem uma interessante análise, e evidenciam a apropriação da obra do autor pela EA muito mais a partir de sua obra "A poética do espaço", do que de suas obras de caráter mais científico e filosófico, onde a questão epistemológica é mais destacada.

O trabalho A Presença de Gaston Bachelard na Área de Educação Ambiental: uma revisão em periódicos nacionais (T 16), de Gladis T. Slonski (IFSC e PPGECT/SC) e Juliana Rezende Torres (UFSCar- Sorocaba) apresenta os resultados de uma pesquisa realizada em periódicos de Educação Ambiental, de circulação nacional, e tem como objetivo "investigar a presença das ideias de Bachelard nos periódicos científicos de EA que circulam no Brasil, de modo a entender como esse referencial teórico está sendo utilizado nos estudos de EA", com o "intuito de contribuir com as discussões e reflexões sobre as bases epistemológicas da EA" (SLONSKI; TORRES, 2015, p.5)

Foram selecionados os periódicos científicos de Educação Ambiental: Ambiente \& Educação (A\&E), Educação Ambiental em Ação (EA em AÇÃO), Pesquisa em Educação Ambiental (PEA), Revista Brasileira de Educação Ambiental (REVBEA) e Revista Eletrônica do Mestrado de Educação Ambiental (REMEA), entendidos como "importantes meios de divulgação das pesquisas da área de EA” (SLONSKI; TORRES, 2015, p.5).

Por meio da busca nos sites desses periódicos, com a palavra Bachelard nos textos completos, foram identificados "20 artigos publicados entre 2005 e 2013 ". A etapa seguinte "consistiu na leitura dos trabalhos completos com a finalidade de selecionar apenas os artigos que, em alguma medida, relacionassem as idéias de Bachelard com a EA" [...]. "Ao final, 10 artigos foram selecionados para a análise" (SLONSKI; TORRES, 2015, p.5).

A Análise Textual Discursiva (Moraes; Galiazzi, 2011) foi utilizada como instrumento analítico para a análise dos artigos. De acordo com as autoras, a Análise Textual Discursiva

[...] corresponde a uma metodologia de análise de dados e informações de natureza qualitativa com a finalidade de produzir novas compreensões sobre os fenômenos e discursos. Pode ser entendida como um processo auto organizado de construção e de compreensão, em que novos entendimentos emergem de uma seqüência recursiva de três componentes: a unitarização, a categorização e a comunicação (SLONSKI; TORRES, 2015, p.5).

As autoras informam, ainda, que

[...] a classificação didática proposta por Japiassú (1975), que divide a obra de Bachelard em diurna e noturna, foi utilizada como categoria a priori para situar os estudos de EA que se articulam à obra de Bachelard. Deste modo, os estudos de EA relacionados às fases diurna e noturna da obra de Bachelard foram assim classificados por meio da análise das obras que foram citadas ao longo do texto e nas referências. Os artigos que referenciaram as obras de sua vertente científica foram classificados na categoria Bachelard Diurno e as que citaram suas obras poéticas, na categoria Bachelard Noturno (SLONSKI; TORRES, 2015, p.5). 
Além disso, na análise, "também foram criadas categorias chamadas de emergentes por Moraes e Galiazzi (2011), produzidas através da organização de conjuntos de elementos semelhantes em um processo indutivo de caminhar do particular para o geral". (p. 6) Assim, a partir da leitura e análise dos dez artigos "com base nos procedimentos da Análise Textual Discursiva [...] emergiram três categorias: percepção ambiental, filosofia onírica e epistemologia", sendo que "as duas primeiras categorias estão relacionadas com a fase noturna da obra de Bachelard e a terceira, com sua fase diurna [...]" e que "a maioria das publicações, sete artigos, são estudos de percepção ambiental" (SLONSKI; TORRES, 2015, p.7).

Nas considerações finais, as autoras afirmam que

[...] foi possível evidenciar ao longo do trabalho que a epistemologia de Gaston Bachelard ainda é pouco explorada como referencial teórico para o campo da EA. Diferentemente do que acontece no ensino de Ciências, onde as pesquisas exploram o viés epistemológico da obra de Bachelard, na EA sua fase noturna é mais explorada, com destaque para a obra A Poética do Espaço e os estudos de percepção ambiental (SLONSKI; TORRES, 2015, p. 10)

Afirmam, ainda, que puderam observar no campo da EA

[...] a falta de um aprofundamento da vertente epistemológica de Bachelard de modo a contribuir em muito para o debate sobre; quais são os preconceitos e obstáculos que se colocam contra o desenvolvimento do pensamento científico; quais são os limites dos próprios 'paradigmas' científicos [...], quais são os limites de concepções educacionais que buscam trabalhar o real [...]; quais avanços são possíveis ao se considerar a realidade vivida como midiatizadora para a construção de novos conhecimentos; qual o papel do erro nos processos epistemológicos e pedagógicos; qual o papel do diálogo entre saberes em torno de contradições, no processo de enfrentamento da problemática ambiental, e, por fim, qual o papel do conhecimento (sistematizado) no processo de conscientização dos sujeitos, considerando as articulações entre as dimensões local e global (SLONSKI; TORRES, 2015, p. 11).

Os dois trabalhos que apresentamos a seguir fazem uma revisão teórica de autores que sustentam uma análise crítica da sociedade capitalista e de seus desdobramentos em relação à educação ambiental. Os autores buscam elucidar, a partir da bibliografia consultada, os diferentes usos deturpados da EA na função de humanizar o capitalismo, contribuindo, assim, para manter um modelo societário excludente e desigual.

O trabalho Um olhar crítico sobre as tendências em Educação Ambiental frente à crise do capital, de Jeniffer de Souza Faria (UFJF) e Elaine Coelho Cristóvão (UFJF) (T 137) tem como objetivo "apresentar e refletir sobre como perspectivas políticas vêm influenciando as ações em Educação Ambiental, demonstrando que não é possível ter sustentabilidade a partir do atual modelo econômico" (FARIA; CRISTÓVÃO, 2015, p.2).

De acordo com as autoras, o

[...] texto se divide em três partes, além da introdução. [...]. Inicialmente, buscamos apresentar algumas características das perspectivas em Educação Ambiental que corroboram com os pressupostos das teorias políticas e econômicas para amenizar e/ou solucionar os problemas ambientais em um contexto de crise. Posteriormente, enfatizamos o que vem acontecendo na última década, no que diz respeito às influências de uma tendência política que tende a humanizar o capital na tentativa de buscar por soluções e/ou superação da crise socioambiental, mas na verdade alicerça-se numa 'ideologia' voltada para os interesses do desenvolvimento capitalista imbricados em ações e conceitos no âmbito da Educação Ambiental. Finalmente, tecemos algumas considerações sobre o todo (FARIA; CRISTÓVÃO, 2015, p. 2). 
As autoras apresentam as características das vertentes "conservadora, pragmática e crítica" elaboradas por Layrargues e Lima (2011) e enfatizam a superioridade da perspectiva crítica em relação às demais

Nesse contexto, a perspectiva Crítica, a partir de um novo referencial teórico, embasado principalmente nas premissas de Paulo Freire, passa a subsidiar uma leitura problematizadora e contextualizada do real [...]. Eis a essência dessa linha, negada pelas demais. Desvelar os embates (conflitos e problemas ambientais) presentes nas relações de poder para que, numa compreensão complexa do real, instrumentalize os atores sociais para intervir na realidade, permitindo ir além e, a partir da reflexão, construir uma nova compreensão de mundo (FARIA; CRISTÓVÃO, 2015, p.4).

Em relação ao capital humano as autoras afirmam que "[...] podemos dizer que diferentes perspectivas teóricas políticas buscaram incessantemente empregar uma sustentabilidade na lógica desenvolvimentista, ou seja, implementar um processo mais efetivo de 'humanização do capital'” (FARIA; CRISTÓVÃO, 2015, p. 5).

Em seguida, explicam o seu entendimento sobre esse conceito:

O significado de 'humanização do capitalismo', portanto, se insere no contexto contemporâneo, por meio de medidas que maquiam a perversidade da economia de mercado, incorporando a ela sentidos de justiça social. As contradições inerentes dessa concepção política refletem, por exemplo, na elaboração/implementação de Políticas Públicas, as quais não instigam a cultura participativa, mas sim ações individuais e hierarquizadas, voltadas para um público com demandas específicas políticas focalizadas de alívio à pobreza - e ainda responsabilizando-os pela sua condição social" (p.5)

Assim, de acordo com as autoras "A Educação Ambiental nesse ideário passa então a ter seu papel e função deturpados. Nela é depositada a função de implementar práticas educativas que corroborem com a lógica capitalista" (FARIA; CRISTÓVÃO, 2015, p.6).

As autoras encerram o texto, afirmando que

[...] a partir dessas considerações, torna-se imprescindível ter clareza sobre o que se entende e faz em termos de Educação Ambiental, pois ao tomar conhecimento das especificidades de cada vertente, torna-se possível, num primeiro plano, desmistificar o conceito de Educação Ambiental por trás de determinadas ações, práticas pedagógicas e sociais, estratégias de marketing e, até mesmo de visão de mundo. [...] Nesse processo, a conclusão que podemos chegar é a de que nossa postura deve ser de criticidade para com as ações educativas, principalmente no âmbito ambiental, para que ela não se torne um instrumento a serviço da burguesia para perpetuação do modelo político e econômico que vigora (FARIA; CRISTÓVÃO, 2015, p.8).

Quanto ao trabalho $O$ Estado (Re) Produtor do Modo de Produção Capitalista: o caso da Educação Ambiental (T 31), de Leonardo Biage de Andrade (UFJF), Vicente Paulo dos Santos Pinto (UFJF) e Dileno Dustan Lucas de Souza (UFJF), o objetivo enunciado pelos autores é "fazer uma análise parcial acerca da legitimação, por parte do estado, de determinada lógica e prática de Educação Ambiental, que entendemos atende às demandas do capital" (ANDRADE; PINTO; SOUZA, 2015, p. 2).

Os autores explicitam que o

[...] objetivo é fazer uma análise teórica, logo não haverá mergulhos profundos em estudos de casos específicos, ficando restrita a compilação de alguns teóricos acerca da temática Estado demonstrando como que essa instituição serve para legitimar algumas práticas e criminalizar movimentos sociais legítimos". Informam, ainda, que a "análise terá como fundamentação prioritária o materialismo-histórico a partir da leitura e análise de autores como Karl Marx, Friedrich Engels, Antonio Gramsci e E.P. Thompson e que "a perspectiva de Educação Ambiental defendida é crítica e, 
portanto, emancipatória das amarras do sistema socioeconômico em voga [...] (ANDRADE; PINTO; SOUZA, 2015, p. 2).

Apresentam, igualmente, as macrotendências político-pedagógicas da Educação Ambiental no Brasil, elaboradas por Layrargues e Lima (2011): Conservadora, Pragmática e Crítica e, em seguida, uma "análise da perspectiva de Estado referenciado no MaterialismoHistórico". Tendo como referência Montaño (2001), os autores afirmam que "o Estado Moderno é uma criação da sociedade capitalista, não sendo independente do sistema que o criou, servindo, portanto, para atender os interesses da classe burguesa, garantir a propriedade privada, sob a égide da 'liberdade' individual' (ANDRADE; PINTO; SOUZA, 2015, p.3).

Nas considerações finais os autores afirmam que

[...] os militantes de uma Educação Ambiental Crítica, com viés emancipador e que se coloca contrário a esse sistema (Estado), sofre com os mesmos empecilhos e repressões impostas por um Estado, que tem para si a legitimação da coerção física, e objetiva aumentar o consumo, e reproduzir um modelo de educação ambiental individualista de práticas ingênuas, fomentando os interesses da classe hegemônica (ANDRADE; PINTO; SOUZA, 2015, p.7).

Outro texto que expressa a pesquisa documental analisa o debate modernidade/pósmodernidade a partir da seleção e leitura de teses e dissertações em EA. As autoras concluem, afirmando que encontraram nos trabalhos analisados o anseio em modificar a modernidade. Esta é uma questão importante e que já foi tema central do IV EPEA, realizado em julho de 2007, na UNESP de Rio Claro.

O trabalho intitulado Contribuições do debate Modernidade/Pós-Modernidade sobre a crise socioambiental: um estudo sobre a produção teórica em Educação Ambiental (T 51), de Maria Fernanda Zanatta Zupelari e Rosa Maria Feiteiro Cavalari tem como intenção

[...] identificar e analisar como o debate da Modernidade/Pós-Modernidade contribui para a compreensão da crise socioambiental, a partir das relações estabelecidas entre estes elementos pela pesquisa acadêmica sobre Educação Ambiental no Brasil. Para tanto, foi feito um recorte a partir da análise de trabalhos selecionados no Banco de Teses do Projeto "Educação Ambiental no Brasil: análise da produção acadêmica (teses e dissertações) (ZUPELARI; CAVALARI, 2015, p.3).

Para a constituição do corpus documental,

[...] de um total de 362 resumos identificados pelas buscas no Catálogo do Projeto, somente vinte trabalhos atendiam aos critérios definidos [...]. Foram selecionados os trabalhos que relacionavam o debate da Modernidade/Pós-Modernidade com a crise socioambiental como foco principal ou secundário de estudo. A partir desse critério, dezessete trabalhos foram selecionados e constituem o corpus documental dessa investigação (ZUPELARI; CAVALARI, 2015, p.5).

As autoras explanam que, dos dezessete trabalhos analisados, treze são dissertações de mestrado e quatro, teses de doutorado, defendidos entre os anos de 1992 e 2009, em quatorze instituições de ensino e pesquisa diferentes, com predomínio da região Sudeste, $50 \%$ dos trabalhos, seguida da região Sul, $35 \%$, da região Centro-Oeste, $10 \%$ e da região Norte, $5 \%$. A concentração de trabalhos defendidos nas regiões Sudeste e Sul tem sido apontada por vários pesquisadores e se explica em função da concentração de Universidades públicas nessas regiões do país.

A partir da análise desses documentos, as autoras concluem que

[...] o debate Modernidade/Pós-Modernidade está presente nas pesquisas sobre Educação Ambiental no Brasil, e que tece relações entre a crise socioambiental e a crise da modernidade. [...]" a crise é compreendida como complexa, de diferentes e complementares escalas, e que deve ser trabalhada como uma crise dos conhecimentos privilegiados pela civilização moderna". No entanto, afirmam as autoras, "mesmo que profunda e difícil de intervir, a crise também pode ser fonte de 
esperança e oportunidades para a construção de formas de conhecer e intervir na natureza e em outras sociedades que prezam pelo equilíbrio (ZUPELARI; CAVALARI, 2015, p. 12).

Além disso, afirmam, ainda, que

[...] existe um consenso entre os trabalhos analisados que algumas características modernas (as dualidades corpo espírito; natureza e ser humano; a fragmentação da realidade; a superespecialização do conhecimento) terão que ser superadas por outras para que se possa de fato construir relações menos opressoras entre as pessoas, e entre sociedade- e natureza, e assim, diminuir as desigualdades sócioambientais e a exploração desenfreada dos recursos naturais e humanos (ZUPELARI; CAVALARI, 2015, p.12).

As autoras encerram o artigo, apontando que "pode-se perceber a existência de uma aspiração da pesquisa brasileira em Educação Ambiental, por parte dos trabalhos analisados, no sentido de modificar a Modernidade" (ZUPELARI; CAVALARI, 2015, p. 13).

As conclusões apresentadas pelas autoras nos remetem, no entanto, à advertência de Silvio Gallo (2008) quando, na conferência de abertura do IV EPEA, dizia

Procurei trazer elementos para o debate sobre a tensão modernidade/pósmodernidade de modo a deslocá-la dessa decisão que me parece tão pouco operativa: optar por um lado ou por outro.

Procurei desmontar a lógica dos argumentos em torno do assim chamado "pósmodernismo", na medida em que ele parece não ter a força e a intensidade do conceito, em sentido filosófico. Porem, não podemos nos fazer cegos às questões que ele nos coloca. [...] Investigar a fundo o projeto moderno, tanto em seus aspectos epistemológicos quanto em seus aspectos políticos; investigar a fundo também as propostas contemporâneas, identificadas ou não como pós-modernismo, também em seus aspectos políticos e epistemológicos [...]. Em suma, agir de modo que a tensão não nos impeça de pensar. Que o pensamento e a ação criativa e produtiva sigam possíveis em educação (GALLO, 2008, p.57).

Os últimos dois textos que apresentamos, a seguir, envolvem outra questão recorrente no GDP e, também, nos encontros de pesquisa em EA, o desafio de transitar das epistemologias próprias de campos do saber mais específicos e a questão ambiental entendida em sua característica interdisciplinar.

Um dos trabalhos discute a necessidade da inclusão da temática ambiental na formação do assistente social e, ainda de forma inicial, busca analisar a estrutura curricular dos cursos de Serviço Social na forma que se segue. Trata-se de O Processo de Formação Ambiental do Assistente Social: indícios curriculares (T164), de Tatiana Ferreira dos Santos (UFS) e Maria Inêz Oliveira Araújo (UFS); as autoras apresentam parte de uma pesquisa em desenvolvimento, cujo objetivo é "explicitar o processo de formação ambiental no contexto da formação do Assistente Social na Universidade Federal de Sergipe - UFS e na Universidade Tiradentes -UNIT" (SANTOS; ARAÚJO, 2015, p.1).

De acordo com as autoras, a pesquisa "configura-se em uma abordagem qualitativa do tipo exploratória" e busca

[...] identificar na estrutura curricular dos cursos de Serviço Social, em Sergipe, disciplinas que apresentem indícios e abordagens sobre a questão ambiental; verificar as concepções dos professores sobre as relações socioambientais e a questão ambiental, partindo do ponto de vista curricular; descrever a relevância de um currículo que contemple discussões e reflexões sobre a problemática ambiental na formação do Assistente Social. (p. 3) 
Para tanto, como próximas etapas da pesquisa, serão analisados os Projetos políticos Pedagógicos dos cursos e serão realizadas entrevistas semiestruturadas com seis professores, sendo três de cada instituição para a identificação das concepções dos professores.

De acordo com as autoras, "apesar de a pesquisa se encontrar em andamento, foi possível o levantamento das publicações de pesquisadores, estudantes e profissionais de Serviço Social sobre a temática ambiental” (SANTOS; ARAÚJO, 2015, p.4).

Além disso, explicam que

[...] o estado da arte pôde evidenciar a urgência da inserção da dimensão ambiental na formação do Assistente Social. Ainda assim, as evidências das produções citadas puderam sustentar a necessidade de averiguar os currículos dos cursos em Sergipe diante da eminente questão ambiental já inserida no cotidiano do Assistente Social, cujo despreparo afeta diretamente na sociedade onde atua. Pôde-se evidenciar, também, indícios que demonstram a realidade curricular dos cursos em questão, conjeturando-se na urgência de atualização necessária que reflita na atuação dos futuros assistentes sociais considerando a questão ambiental entremeada à questão social e vice-versa (SANTOS; ARAÚJO, 2015, p.4)

$\mathrm{O}$ artigo é finalizado com o item breves considerações, no qual as autoras afirmam que

[...] espera-se, com essa pesquisa em andamento, contribuir com as bases da formação do Assistente Social, principalmente no que diz respeito ao cenário atual [...] que sirva de cerne na condução de outras pesquisas e estimule discussões sobre a temática ambiental tão carente do Serviço Social. Além disso, anseia-se com este estudo, que a questão ambiental seja entendida como objeto de trabalho do assistente social e possa ser inserida na formação profissional como base essencial para a compreensão da questão social e vice-versa. A questão ambiental está entremeada com a questão social. [...] A comunidade carece, a realidade exige, precisamos de profissionais reparados para atuar na questão ambiental e caber a nós, assistentes sociais, demandarmos por uma formação qualificada e atualizada (SANTOS; ARAÚJO, 2015, p. 13).

Por fim, o último trabalho, na modalidade da pesquisa documental, busca elucidar as interfaces entre ecologia e EA. Intitulado As 'Ecologias' Presentes nas Pesquisas em Educação Ambiental (T176), a autoria é de Vanessa Lima Bomfim (FFCLRP-USP) e Clarice Sumi Kawasaki (FFCLRP-USP).

O trabalho em questão "aborda as possíveis interfaces" entre ecologia e Educação Ambiental, "buscando compreender a multiplicidade de abordagens ecológicas que interagem e se manifestam nas pesquisas em Educação Ambiental"'(p.1). A pesquisa, em desenvolvimento, se insere em um projeto mais amplo, interinstitucional - A Educação Ambiental no Brasil - análise da produção acadêmica (dissertações e teses -Projeto EArte) que envolve pesquisadores de três universidades públicas do Estado de São Paulo, cujo objetivo é "identificar, diagnosticar, mapear e estudar a produção acadêmica em EA do Brasil, focalizando teses e dissertações, abrangendo, até o momento, o período de 1987 a 2009" (BOMFIM; KAWASAKI, 2015, p.7).

A partir do Banco de Teses do referido projeto "buscou-se o conjunto de teses e dissertações em EA que fazem uma interface com a (s) Ecologia(s)" por meio do "radical ecolog nos campos "Título, Programa de Pós, Palavras-Chave, Resumo e Tema ambiental, totalizando 545 trabalhos, com o radical em, ao menos, um dos campos citados" (BOMFIM; KAWASAKI, 2015, p.7).

De acordo com as autoras, em análise preliminar pode-se perceber

[...] que um número significativo destes trabalhos, apesar da presença do radical ecolog ou mesmo do termo ecologia, não abordou aspectos da Ecologia, restringindo-se ao uso coloquial do termo e de palavras derivadas. Portanto, em uma etapa posterior foram selecionadas as 168 teses e dissertações referindo-se direta e 
explicitamente à Ecologia em um dos três campos: Título, Palavras-Chave, Resumo. Para a análise optou-se por considerar o que se chamou de Ecologia em dois grandes grupos: a) a 'Ciência Ecologia', compreendendo a Ecologia Natural e a Ecologia Humana e b) as 'Outras Ecologias', que apresentam abordagens para além das Ciências Biológicas, compreendendo, por exemplo, a 'Ecologia Profunda', a 'Ecologia Social' e a 'Ecologia Política', entre outras (BOMFIM; KAWASAKI, 2015, p.8).

Bomfim e Kawasaki (2015, apud BARDIN, 2011) relatam ter utilizado como instrumento analítico a Análise de Conteúdo. Na apresentação dos resultados, as autoras, inicialmente, elaboram uma caracterização do corpus documental em relação aos seguintes aspectos: "Ano de Defesa, Regiões, Dependências Administrativa, Programa de PósGraduação, Grau de Titulação Acadêmica, Contexto Educacional da Pesquisa e Tema de Estudo da Pesquisa" (p.8).

De acordo com as autoras,

[...] no grupo denominado 'Ciência Ecologia' foram identificadas 34 teses e dissertações, utilizando diferentes denominações, tais como 'Ecologia Humana' (13), 'Ecologia Aplicada' (2), 'Ecologia da Espécie' (2),'Ecologia Biológica' (1), 'Ecologia da Floresta (1),'Ecologia do Açude' (1), 'Ecologia do Anopheles' (1), 'Ecologia dos Ecossistemas' (1), 'Ecologia e Ficologia' (1), Ecologia e Liminologia' (1), 'Ecologia Pantaneira'(1). Nove teses e dissertações de Ensino de Ecologia foram incluídos no grupo, por indicarem uma abordagem de ciência". [...] As teses e dissertações em 'Ecologia Humana' foram agrupadas em 'Ecologia Científica' por apresentarem abordagens desta, mas que nem sempre excluem definitivamente as outras (BOMFIM; KAWASAKI, 2015, p.11).

E, ainda:

[...] no grupo 'Outras Ecologias' foram incluídas as teses e dissertações que se apresentaram com a denominação' Ecologia Social' que aparecem em sete trabalhos, 'Ecologia Profunda' (6),'Ecologia Política (3),'As três Ecologias' (2) e ainda denominações como 'Ecologia Complexa' (1), 'Ecologia Expandida' (1) e 'Ecologia transcendendo a dimensão científica'(1). A Agroecologia aparece em 20 trabalhos e a Etnoecologia em 4 trabalhos (BOMFIM; KAWASAKI, 2015, p.12).

Bomfim e Kawasaki (2015, p.12) informam que "um número significativo de teses e dissertações (78) não puderam ser classificadas nos agrupamentos anteriores, já que não oferecem informações suficientes para esta classificação".

Encerram o artigo, reiterando que

[...] confirmou-se que Ecologia presente nesses trabalhos não apresenta um significado único nem representa uma área uniforme ou conjunto de conhecimentos homogêneos. O termo ecologia teria antes a conotação de uma estrutura radial, da qual partem diversos caminhos, originados numa base comum central. Neste ponto pode-se inferir que a 'Ecologia' ultrapassa os limites originais da ciência como estudo da natureza e estabelece relações com outros aspectos como os sociais (BOMFIM; KAWASAKI, 2015, p.12).

Além disso, informam as autoras, que

[...] este trabalho conjectura que a EA realmente deve se expandir englobando fatores sociais, históricos, culturais, filosóficos, políticos e econômicos, o que não significa que a Educação Ambiental tenha que ignorar os conhecimentos da ciência Ecologia sobre o funcionamento dos sistemas vivos e suas interações. Considera-se que o conhecimento e compreensão das questões ambientais e, consequentemente a aplicação bem-sucedida da Educação Ambiental, passa pelo entrelaçamento de ciências diversas, incluindo a Ecologia, e envolvendo fatores múltiplos e complexos destas diferentes formas de conhecimento (BOMFIM; KAWASAKI, 2015, p.12). 
Nesse texto verificamos, também, a compreensão de que a EA não pode se furtar a trabalhar com os aportes das diferentes ciências entre elas a ecologia, de maneira a contemplar os aspectos "sociais, históricos, culturais, filosóficos, políticos e econômicos", que a temática ambiental comporta.

Esta detalhada apresentação dos trabalhos se fez necessária porque, no nosso entendimento, tanto nos textos quanto nas discussões, que se seguiram no âmbito do GDP, transbordaram para as plenárias ao longo do VIII EPEA e retomaram preocupações que tem sido recorrentes. Os jovens pesquisadores se ressentem das lacunas em suas formações, tanto nos bacharelatos quanto nas licenciaturas de uma articulação maior entre os conhecimentos específicos de cada área e as contribuições do campo pedagógico. Por outro lado, observam a necessidade de aprofundarmos nas pesquisas da EA a compreensão do que se entende por uma Educação Ambiental Crítica. Para além da declaração política de pertencimento ao campo crítico, todos enfatizaram a necessidade de maior explicitação teórica dos conceitos e categorias que embasam tais afirmações, bem como, maior rigor metodológico na apropriação das diferentes correntes epistemológicas. Tal explicitação e rigor se justificam na medida em que

\begin{abstract}
Entendemos que o embate teórico-metodológico nas formas de apreender o real é parte integrante na luta contra-hegemônica. A contradição capital-trabalho não é um fenômeno que começa e se esgota com a segunda revolução industrial, ela está presente nas lutas entre as diferentes classes sociais ao longo da história do capitalismo até nossos dias. Também na esfera da produção do conhecimento nos deparamos com os reflexos dessas contradições, que explicitam assim o caráter ideológico e alienante do pensamento único, da ciência pretensamente neutra, das verdades ditas universais. Todos eles momentos de uma teoria que desconsidera a realidade material em que foi produzida. (TREIN, 2007, p. 124)
\end{abstract}

O encontro propiciou, ainda, diversos debates sobre as condições materiais que enfrentamos no âmbito das universidades, mais especificamente de pós-graduação, para que possamos consolidar um campo de conhecimento que é estratégico, como nos diz Leher (2015, p.34): "para as reflexões das proposições alternativas que as lutas socioambientais, dentro e fora da escola e das universidades, precisam anunciar para enfrentar a barbárie do novo ciclo capitalista dependente".

\title{
4 Considerações Finais
}

Ao apresentarmos, por meio deste artigo, as discussões ocorridas no interior do GDP Pesquisa em Educação Ambiental e questões epistemológicas, reunido por ocasião do VIII EPEA, realizado no Rio de Janeiro, em julho de 2015, nosso objetivo muito mais do que pretender esgotar as problemáticas apontadas e cristalizá-las em conclusões definitivas, é dar continuidade a um fecundo e necessário debate instaurado já há algum tempo, envolvendo os pesquisadores da área.

Assim, na tentativa de contribuir para a continuidade do debate, faz-se necessário aprofundarmos nossas reflexões no sentido de explicitarmos o que entendemos por uma perspectiva crítica em Educação Ambiental, uma vez que, como apontado nesse artigo, a maioria dos trabalhos apresentados no GDP se filia a essa perspectiva, embora nem todos a explicitem de maneira clara. Nesse sentido, a questão "a educação ambiental crítica é crítica de quê?", formulada por Trein (2012a) continua a nos desafiar e a exigir resposta.

Tal resposta, como já apontado neste artigo, deve ir além da declaração de fé do pertencimento ao campo da teoria crítica, deve buscar a explicitação teórica dos pressupostos adotados, bem como um maior rigor na apropriação das diferentes correntes epistemológicas. 


\section{Referências}

FLORIANI, D. Educação ambiental e epistemologia: conhecimento e prática de fronteira ou uma disciplina a mais? Pesquisa em educação Ambiental, Rio Claro, v.4. n.2, p.191-202, Jul./Dez. 2009.

FREITAS, L. C. de. Os reformadores empresariais da educação e a disputa pelo controle do processo pedagógico na escola. Educação e sociedade, Campinas, v.35, n.129, p.1085-1114, Out./Dez, 2014.

GALLO, S. Pesquisa em Educação: o debate modernidade e pós-modernidade. Pesquisa em Educação Ambiental, Rio Claro, v.3, n.1, p. 33-58, 2008.

LEHER, R. Apresentação. Educação ambiental como crítica ao desenvolvimento sustentável: desafio dos movimentos e das lutas sociais. In: LOUREIRO, C. F. B.; LAMOSA, R. de A. C. (Orgs.). Educação Ambiental no Contexto Escolar: um balanço crítico da Década da educação para o desenvolvimento Sustentável. Rio de Janeiro: Quartet/CNPq, 2015.

TREIN, E.; CAVALARI, R. M. F. Pesquisa em Educação Ambiental e Questões Epistemológicas: a permanência e a renovação. Pesquisa em Educação Ambiental, v.9, n.1, p. 120-132, 2014.

TREIN, E. A contribuição do pensamento marxista à educação ambiental. In: LOUREIRO, C. F. B. et al Orgs.).Movimento Ambientalista e Pensamento Crítico. Rio de Janeiro: Quartet, 2007.

TREIN, E. Pesquisa em educação Ambiental e Questões Epistemológicas: questões levantadas no GDP. Pesquisa em educação Ambiental, Rio Claro, v.7, n.2, p. 79-89, jul/dez. 2012.

TREIN, E. A Educação Ambiental Crítica: crítica de quê? Revista Contemporânea de Educação, Rio de Janeiro, v.7, n. 14, p.304-318, Ago./Dez. 2012a.

\section{Relação dos Trabalhos inscritos no GDP “Educação Ambiental e Questões Epistemológicas”}

ANDRADE, Leonardo Biage de, PINTO, Vicente Paulo dos Santos, SOUZA, Dileno Dustan Lucas de. O Estado (Re) Produtor do Modo de Produção Capitalista: o caso da Educação Ambiental (T31).

BOMFIM, Vanessa Lima, KAWASAKI, Clarice Sumi. As "ecologias" presentes nas pesquisas em Educação Ambiental (T 176).

COSTA, César Augusto, LOUREIRO, Carlos Frederico Bernardo. Interculturalidade, exclusão e libertação em Paulo Freire na leitura de Enrique Dussel: aproximações para a pesquisa em educação ambiental crítica (T3).

FARIA, Jeniffer de Souza, CRISTÓVÃO, Elaine Coelho. Um olhar crítico sobre as tendências em Educação Ambiental fente a crise do capital (T 137).

SANTOS, Tatiana Ferreira dos, ARAÚJO, Maria Inês Olveira. O processo de formação ambiental do assistente social: indícios curriculares (T 164).

SLONSKI, Gladis Teresinha, TORRES, Juliana Rezende. A presença de Gaston Bachelard na área de Educação Ambiental: uma revisão em periódicos nacionais (T16).

TEIXEIRA, Dinair Velleda. Reflexões epistemológicas sobre a publicidade sustentável: pesquisa de tese realizada na década da educação para o desenvolvimento sustentável (T 222).

ZUPELARI, Maria Fernanda Zanatta, CAVALARI, Rosa Maria Feiteiro. Contribuições do debate Modernidade/Pós-Modernidade sobre a crise socioambiental: um estudo sobre a produção teórica em Educação Ambiental (T51). 